\title{
Screening of Danish blood donors for hepatitis B surface antigen using a third generation technique
}

\author{
PER WANTZIN, JENS O NIELSEN, NIELS TYGSTRUP, HENNING SOERENSEN, \\ ESBEN DYBKJAER
}

\begin{abstract}
The profit to be gained by testing Danish blood donors for hepatitis $B$ surface antigen (HBsAg) with a third generation technique instead of the currently used immunoelectrophoresis was investigated by additional screening of 48750 blood units by radioimmunoassay three weeks after donation. Twenty nine units were positive for HBsAg on radioimmunoassay (0.059\%). Only six of these were found by immunoelectrophoresis $(0.012 \%)$. Most of the 23 donors positive on radioimmunoassay and negative on immunoelectrophoresis were healthy carriers of $\mathrm{HBsAg} \mathrm{(20)}$ or had asymptomatic chronic liver disease (two). One donor had acute hepatitis B. Fifteen of the 23 blood units were transfused. The 15 recipients were monitored biochemically and serologically for up to nine months. One recipient developed fulminant hepatitis $B$, three developed acute hepatitis $B$, and one became a healthy carrier of HBsAg. All these patients had received blood from healthy carriers of HBsAg. Two recipients were immunised against $\mathrm{HBsAg}$, and in one patient no seroconversion was observed. The remaining recipients died soon after transfusion or were protected by antibodies to $\mathrm{HBs} \mathrm{Ag}$ that had been present before the transfusion.
\end{abstract}

Testing of Danish blood donors using a third generation technique identified a substantial number of donors positive for HBsAg overlooked by immunoelectrophoresis. Most of these donors were healthy carriers of HBsAg. Blood taken from such carriers is highly infectious when transfused, probably because of the large amount of material transmitted.

\section{Introduction}

During the past decade routine screening of Danish blood donors for hepatitis B surface antigen (HBsAg) has been by immunoelectrophoresis. The use of this rather insensitive test for detecting HBsAg has been justified by the fact that the incidence of hepatitis B is low in Denmark compared with many other countries. Only 10-20 cases of hepatitis B associated with transfusion are registered each year. In countries with a high prevalence of HBsAg the use of third generation techniques (radioimmunoassay and enzyme methods) can show the presence

Rigshospitalet, University of Copenhagen, Blegdamsvej 9, DK-2100 Copenhagen, Denmark

PER WANTZIN, MD, research fellow, department of clinical immunology and blood bank

JENS O NIELSEN, MD, PHD, consultant, department of infectious diseases NIELS TYGSTRUP, MD, PHD, professor of medicine, medical department A HENNING SOERENSEN, MD, PHD, deputy director, department of clinical immunology and blood bank

Department of Clinical Immunology and Blood Bank, Hvidovre Hospital, University of Copenhagen

ESBEN DYBKJAER, MD, director

Correspondence to: Dr Wantzin. of HBsAg in $0.06-0.3 \%$ of donors who yield negative results on immunoelectrophoresis, ${ }^{12}$ and it has been reported that testing for $\mathrm{HBs} A g$ using third generation techniques in areas of high prevalence substantially reduces hepatitis B associated with transfusion. ${ }^{2} 3$ These highly sensitive tests are now recommended for routine screening of donors in the United States and most countries in western Europe. The profit to be gained from introducing third generation techniques in areas of low prevalence like the Scandinavian countries, however, is unknown. Most of the donors who yield positive results on testing for $\mathrm{HBsAg}$ in these countries are healthy carriers of $\mathrm{HBsAg}{ }^{4}$ and the potential risk of infection from using their blood in transfusions is still not clear. In this study we determined the prevalence of blood donors positive for $\mathrm{HBsAg}$ who were detectable only by radioimmunoassay and investigated whether blood from these donors caused infection.

\section{Methods}

We received serum samples from all units of blood gathered in the Copenhagen area from 4 January to 7 June 1982 for additional testing for $\mathrm{HBsAg}$ by third generation technique (Ausria II-125, Abbott). We registered the age and sex of each donor and whether he or she had been tested for HBsAg by immunoelectrophoresis or a third generation technique previously. The radioimmunoassay was performed 21 days after the serum sample had been received, at which time the blood unit would have been either used or discarded. Serum samples that were repeatedly positive for $\mathrm{HBsAg}$ were tested for hepatitis B e antigen ( $\mathrm{HBeAg}$ ), antibody to $\mathrm{HBeAg}$ (anti-HBe), and antibody to hepatitis B core antigen (anti-HBc) (Abbott HBe-TM and Corab, Abbott). If $\mathrm{HBeAg}$, anti-HBe, and anti-HBc could not be detected the Ausria confirmatory neutralisation test (Abbott) was performed.

All donors positive for $\mathrm{HBsAg}$ accepted a follow up examination. The donors answered a questionnaire concerning exposure to hepatitis, intravenous drugs, blood transfusions, homosexuality, and symptoms of liver disease and were examined for clinical signs of liver disease. In addition, blood samples were drawn for routine biochemical tests and analysis for hepatitis B virus. Routine biochemical tests included measurements of bilirubin, albumin, and immunoglobulin (IgA, IgM, and IgG) concentrations, alanine aminotransferase and alkaline phosphatase activities, and prothrombin/proconvertin time. A decision based on this evaluation was made whether to recommend a liver biopsy.

Recipients of blood positive for HBsAg were informed that one of the units of blood that they had received might have contained hepatitis B virus. All recipients accepted follow up at 4, 6, 8, 10, $12,15,18,21,24$, and 36 weeks after transfusion, at which time samples of blood were drawn for measurement of alanine aminotransferase activity and analysis for hepatitis $B$ virus. The appearance of $\mathrm{HBsAg}$ or raised alanine aminotransferase activity was followed by weekly examinations to confirm suspected acute hepatitis B.

Ethics-The study was approved by the Danish Medical Research Council, which at the time acted as the ethical committee for medical research in Denmark. The study was considered to be ethically justified for the following reasons: (1) during the period of the study blood donors were not examined routinely by third generation tests in Denmark and thus the study did not interfere with current practice; (2) a low value of $\mathrm{HBsAg}$ in blood-for example, in blood that is negative on immunoelectrophoresis-is not necessarily associated with the presence of the complete hepatitis B virus genome in the blood; and (3) introduction of a third generation technique as routine testing would impose considerable expense on the health service and should therefore be avoided in the absence of detectable benefit. 


\section{Results}

During the study 48750 units of blood were tested for HBsAg by radioimmunoassay. Of the corresponding donors, $4601(9.4 \%)$ were giving blood for the first time and therefore had presumably never been tested for $\mathrm{HBsAg}$ before; $37105\left(76 \cdot 1^{\circ} \%\right)$ had previously been tested by immunoelectrophoresis; and $7044(14 \cdot 4 \%)$ gave blood twice during the study and thus at their second attendance had already been tested by radioimmunoassay. HBsAg was found in 29 blood units $(0.059 \%)$. The sex ratio (men to women) was 13.5 and the median age 35 years (range 19-55).

Twenty three of the units positive for $\mathrm{HBsAg}$ were detected only by radioimmunoassay $\left(0.047^{\circ}\right)$, whereas six units were also found by the routine screening using immunoelectrophoresis $(0.012 \%)$. Twenty of the 23 donors who were positive on radioimmunoassay and negative on immunoelectrophoresis were shown to be healthy carriers of HBsAg. These donors were serologically characterised by the presence of $\mathrm{HBsAg}$, anti-HBe, and anti-HBc with only minor differences in the $\mathrm{S} / \mathrm{N}$ ratio ( $\mathrm{HBsAg}$ ) - that is, the number of counts per minute in the sample divided by the mean number of counts per minute in the negative controls-and in the percentages of inhibition (anti-HBe and anti-HBc) at donation and follow up. They had no symptoms or signs of liver disease, and no biochemical abnormalities. One donor was borderline positive for $\mathrm{HBsAg}$ at donation without detectable $\mathrm{HBeAg}$, anti-HBe, or anti-HBc. The $\mathrm{HBsAg}$ reaction was confirmed by neutralisation. At follow up this donor was still positive for $\mathrm{HBsAg}$ and had become positive for $\mathrm{HBeAg}$, showing symptoms and biochemical abnormalities compatible with acute hepatitis. Of the remaining two donors who were positive on radioimmunoassay and negative on immunoelectrophoresis, one had chronic persistent hepatitis and one had cirrhosis as verified by liver biopsy. At donation these donors were positive for anti-HBe; at follow up both were asymptomatic but had moderately raised alanine aminotransferase activity. Of the six donors who were positive on both radioimmunoassay and immunoelectrophoresis, four were healthy carriers of $\mathrm{HBsAg}$ and two had chronic persistent hepatitis $\mathbf{B}$.

Six blood units were positive on radioimmunoassay, but the reactions proved to be false positive. No other serological markers of hepatitis $B$ virus could be detected. Four of the reactions were not confirmable by neutralisation, whereas two were shown to be true positives by this test. At follow up only one of the donors reacted positively for HBsAg, but the reaction could still not be confirmed by neutralisation. All six donors were still non-reactive for antibody to $\mathrm{HBsAg}$ (anti-HBs), anti-HBe, and anti-HBc, and showed no clinical or biochemical abnormalities.

The table shows the 23 donors who were positive on radioimmunoassay and negative on immunoelectrophoresis and the six who were positive on both distributed according to previous testing for HBsAg. In donors who had not been tested previously the prevalence of $\mathrm{HBs} A g$ was $0.13 \%$. In half of the donors in this group HBsAg was detectable only by the third generation technique. In donors who had been tested by immunoelectrophoresis the prevalence of $\mathrm{HBsAg}$ was $0.062^{\circ}{ }_{0}$. In most of these donors $(20 / 23) \mathrm{HBsAg}$ was detectable only by radioimmunoassay. In this group of donors the prevalence of HBsAg found by radioimmunoassay was significantly higher than the prevalence found by immunoelectrophoresis $\left(p<0.0001, \chi^{2}\right.$ test). No significant difference was found in the prevalences of donors who were positive on radioimmunoassay and negative on immunoelectrophoresis between the groups of donors who had and had not been tested by immunoelectrophoresis before. In the group of donors who had been tested previously by both immunoelectrophoresis and radioimmunoassay no donors positive for $\mathrm{HBsAg}$ were observed.

Fifteen of the 23 blood units that were positive on radioimmunoassay and negative on immunoelectrophoresis were transfused: of eight units obtained from the group of donors who were healthy carriers of HBsAg, five were outdated and three were discarded. The disclosure of the presence of $\mathrm{HBsAg}$ and consequent discarding of the blood in

these three cases was due to supplementary testing by a third generation technique in two cases (because the donor was implicated in a case of hepatitis B associated with transfusion and because the plasma unit was intended for production of factor VIII, respectively) and in one case was because the donor underwent plasmapheresis twice in three weeks (to obtain antibodies against varicella virus) and at the second plasmapheresis $\mathrm{HBsAg}$ was found on screening by immunoelectrophoresis.

Thus fifteen patients received blood that was positive on radiommunoassay and negative on immunoelectrophoresis. Twelve of these blood units came from healthy carriers of HBsAg. Among the 12 recipients of these units, four developed acute hepatitis $B$, which became fulminant and fatal in one case; the remaining three patients developed symptoms and required admission to hospital but otherwise had an uncomplicated course. A further patient became a healthy carrier of $\mathrm{HBsAg}$, one was immunised against hepatitis B virus-that is, seroconversion took place without biochemical abnormalities or symptoms of liver disease-and one had presumably been positive for anti-HBs at the time of transfusion as anti-HBs was already present in a high titre at the first follow up examination. Four patients died from their primary disease without developing hepatitis (after four days, four days, four weeks, and 16 weeks). The patient who died 16 weeks after transfusion was positive for $\mathrm{HBsAg}$ for several weeks before death but showed no clinical or biochemical signs of acute hepatitis. Postmortem liver biopsy specimens showed no histological abnormality. In a 6 week old girl nothing happened either serologically or biochemically.

Of the three patients who received blood from the donors with acute hepatitis $\mathrm{B}$, chronic persistent hepatitis $\mathrm{B}$, and cirrhosis positive for $\mathrm{HBsAg}$, respectively, the first died five days after transfusion, the second was positive for anti-HBs before the transfusion, and the third was immunised against hepatitis $B$ virus.

\section{Discussion}

In this study HBsAg was detected in $0.059 \%$ of the blood donors by radioimmunoassay compared with $0.012 \%$ by immunoelectrophoresis-that is, there was a fivefold increase in the detection of blood donors positive for $\mathrm{HBsAg}$ when radioimmunoassay was used instead of immunoelectrophoresis. This difference, however, applies only to a population of donors who have not been tested by radioimmunoassay before. In time the rate of detection of $\mathrm{HBsAg}$ by radioimmunoassay will decrease owing to the lower prevalence in repeat donors compared with first time donors. In the group of first time donors the prevalence of $\mathrm{HBsAg}$ was $0.13 \%$ by radioimmunoassay and $0.065 \%$ by immunoelectrophoresis. Thus the estimated profit in using radioimmunoassay instead of immunoelectrophoresis is a twofold increase in the detection of HBsAg. This is in accordance with the findings of Dodd, who estimated that radioimmunoassay resulted in a $49 \%$ increase in the detection of donors who were positive for $\mathrm{HBsAg}$ compared with immunoelectrophoresis.

Twenty two $(96 \%)$ of the 23 donors positive for HBsAg who were detected only by radioimmunoassay were healthy carriers or had asymptomatic chronic liver disease. This high proportion of chronic carriers corresponds with the findings in donors positive for $\mathrm{HBsAg}$ on immunoelectrophoresis. ${ }^{4}$ The fact that only one of the donors positive for HBsAg had acute hepatitis B indicates a very low prevalence of hepatitis B in the Danish donor population and that the profit gained by screening repeat donors in Denmark would be correspondingly small. This differs considerably from the findings of Bastiaans et al, who found that the prevalences of $\mathrm{HBsAg}$ in first time and repeat

\begin{tabular}{|c|c|c|c|}
\hline Previous testing for $\mathrm{HBsAg}$ & Disease & $\begin{array}{l}\text { No }(\%) \text { of donors negative } \\
\text { on immunoelectrophoresis }\end{array}$ & $\begin{array}{l}\text { No }(\%) \text { of donors positive } \\
\text { on immunoelectrophoresis }\end{array}$ \\
\hline $\begin{array}{l}\text { None }(n=4601) \\
\text { Immunoelectrophoresis }(n=37105) \\
\text { Immunoelectrophoresis and radioimmunoassay }(n=7044)\end{array}$ & $\begin{array}{l}\text { Healthy carrier of } \mathrm{HBsAg} \\
\text { Healthy carrier of } \mathrm{HBsAg} \\
\text { Chronic persistent hepatitis } \\
\text { Acute viral hepatitis } \\
\text { Cirrhosis }\end{array}$ & 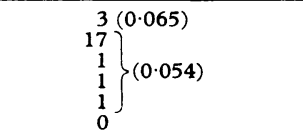 & $\begin{array}{l}\left.\begin{array}{l}3(0.065) \\
1 \\
2\end{array}\right\}(0.008) \\
0\end{array}$ \\
\hline
\end{tabular}


donors among the American Red Cross donor population were $0.208 \%$ and $0.077 \%$ respectively ${ }^{6}$-that is, that the prevalence of $\mathrm{HBsAg}$ in repeat donors was $37 \%$ of the value found in first time donors.

The chief purpose of screening for HBsAg is not to identify blood donors positive for $\mathrm{HBsAg}$ but to reduce hepatitis $\mathrm{B}$ associated with transfusion. Thus the profit to be gained from screening depends not only on the number of donors positive for HBsAg who are identified but also on the infectivity of blood from these donors. As most donors in Denmark who are positive for $\mathrm{HBsAg}$ are healthy carriers of $\mathrm{HBsAg}$ the profit depends mostly on the infectivity in the healthy carrier state. The predominant opinion has been that the presence of $\mathrm{HBeAg}$ indicates active viral replication, so that material positive for $\mathrm{HBeAg}$ is highly infectious whereas material negative for $\mathrm{HBeAg}$ and positive for anti-HBe is non-infectious or carries an extremely low risk of infection. The expected outcome of receiving blood from a healthy carrier of $\mathrm{HBsAg}$ should therefore be immunisation against hepatitis $B$ virus. This study showed, however, that four out of seven recipients susceptible to infection with hepatitis B virus developed acute hepatitis B after receiving blood from a healthy carrier of HBsAg. Thus we conclude that healthy carriers of $\mathrm{HBsAg}$ are highly infectious as blood donors, probably because of the large amount of material transmitted. The system based on the presence of $\mathrm{HBeAg}$ and anti-HBe seems to be of no value in predicting the outcome in recipients of blood positive for $\mathrm{HBsAg}$.

The blood banks that participated in this study were: Rigshospitalet, Koebenhavns Kommunehospital, Bispebjerg Hospital, Hvidovre Hospital, Frederiksberg Hospital, KAS Gentofte, KAS Glostrup, and Storkoebenhavns Frivillige Bloddonorkorps.

We thank Lise Nielsen and Bente Iversen for technical help and Annette Fentz for help in preparing the manuscript.

\section{References}

1 Dodd RY. Hepatitis B (surface) antigen testing by radioimmunoassay. Am 7 Clin Pathol i975;63:847-5

Koretz RL, Gitnick GL. Prevention of post-transfusion hepatitis. Am $\mathcal{F}$ Med $1975 ; 59: 754-60$

Alter HJ, Holland PV, Morrow AG, Purcell RH, Feinstone SM, Moritsugu Y. Clinical and serological analysis of transfusion-associated hepatitis. Lance $975 ;$;i : $838-41$.

Reinicke V, Dybkjaer E, Poulsen H, Banke O, Lylloff K, Nordenfelt E. A study of reference to liver histology. N Engl f Med 1972;286:867-70.

5 Szmuness W, Prince AM, Brotman B, Hirsch RL. Hepatitis $B$ antigen and antibody in blood donors: an epidemiologic study. F Infect Dis 1973;127:17-25.

6 Bastiaans MJS, Dodd RY, Nath N, Pineda-Tamondong G, Sandler SG, Barker LF. Hepatitis-associated markers in the American Red Cross volunteer blood dono population. Vox Sang 1980;39:1-8.

(Accepted 4 fune 1985)

\title{
Screening for antimalarial maculopathy in rheumatology clinics
}

\author{
B W FLECK, A L BELL, J D MITCHELL, B J THOMSON, N P HURST, G NUKI
}

\begin{abstract}
Ophthalmoscopy and three tests of visual function were undertaken in 39 patients with rheumatoid arthritis receiving treatment with antimalarial drugs and in a control group of 16 patients with rheumatoid arthritis who were not receiving such treatment. Visual contrast sensitivity, macular threshold to red light, and central visual fields to red targets were not significantly different in treated patients and controls. There were no abnormalities in visual acuity, but 11 of 76 eyes of treated patients showed minor macular abnormalities on ophthalmoscopy that were not seen in control patients, suggesting that ophthalmoscopy may be the most sensitive measure of early drug toxicity. Five rheumatologists were able to identify 52 of 65 minor changes detected by an ophthalmologist.

These studies, and a critical review of published reports, suggest that in clinical practice antimalarial drugs can be administered safely to patients with
\end{abstract}

Princess Alexandra Eye Pavilion, Royal Infirmary, Edinburgh B W FLECK, MB, FRCSED, registrar

\section{Northern General Hospital, Edinburgh EH5 2DQ}

A L BELL, MD, MRCP, research fellow, rheumatic diseases unit

J D MITCHELL, MB, MRCP, temporary senior lecturer, department of medical neurology

B J THOMSON, MB, MRCP, registrar, rheumatic diseases unit

N P HURST, PHD, MRCP, senior registrar, rheumatic diseases unit

G NUKI, MB, FRCP, professor of rheumatology

Correspondence to: Professor Nuki. rheumatoid arthritis without the need for repetitive routine examination by an ophthalmologist or the use of complicated physiological tests. Recording of visual acuity in each eye and ophthalmoscopy by the prescribing doctor may be all that are required to detect early antimalarial maculopathy.

\section{Introduction}

In the 1960s several reports of corneal deposits and macular damage in patients with rheumatoid arthritis and systemic lupus erythematosus receiving treatment with antimalarial drugs led to the recommendation that all such patients should be regularly examined by an ophthalmologist. ${ }^{1}$ The need to continue this practice must be critically reassessed in the light of clinical experience with low dose treatment.

A review in 1982 of published reports showed only 13 cases of maculopathy with reduced visual acuity in patients taking chloroquine phosphate $250 \mathrm{mg}$ daily, or less, over a period of two to 10 years. ${ }^{2}$ Only four of 99 patients treated with hydroxychloroquine sulphate $400 \mathrm{mg}$ daily, or less, had any evidence of retinal toxicity when followed up prospectively for one to eight years, none developed visual loss, and all abnormalities were completely reversible after the treatment was stopped. ${ }^{3}$ A recent survey carried out in Cleveland, Ohio, showed no cases of maculopathy in 400 patients taking chloroquine phosphate $4 \mathrm{mg} / \mathrm{kg} /$ day or hydroxychloroquine $6.5 \mathrm{mg} / \mathrm{kg} /$ day over a mean period of seven years. ${ }^{4}$ Although comprehensive ophthalmological testing was a feature of each of these studies, the low risks of ocular toxicity with current regimens of antimalarial drug treatment suggest that routine surveillance by ophthalmologists may no longer be necessary.

In this study we compared the value of two standard tests of 